\title{
Exploring a zero food waste system for sustainable residential buildings in urban areas
}

\author{
Jeongik Oh${ }^{1}$, Hyunjeong Lee ${ }^{2+}$ \\ ${ }^{1}$ Land and Housing Institute of the Korea Land and Housing Corporation, Daejeon 34047, Republic of Korea \\ ${ }^{2}$ Department of Housing \& Interior Design, Kyung Hee University, Seoul 02447, Republic of Korea
}

\begin{abstract}
This study explores the environmentally innovative and low-impact technology, a zero food waste system (ZFWS) that utilizes food waste and converts it into composts or biofuels and curtails carbon emissions. The ZFWS not just achieves food waste reductions but recycles food waste into fertilizer. Based on a fermentation-extinction technique using bio wood chips, the ZFWS was employed in a field experiment of the system installed in a large-scale apartment complex, and the performance of the system was examined. The on-site ZFWS consisted of three primary parts: 1) a food waste slot into which food waste was injected; 2) a fermentation-extinction reactor where food waste was mixed with bio wood chips made up of complex enzyme and aseptic wood chips; and 3) deodorization equipment in which an ultraviolet and ozone photolysis method was employed. The field experiment showed that food waste injected into the ZFWS was reduced by $94 \%$. Overall microbial activity of the food waste in the fermentation-extinction reactor was measured using adenosine tri-phosphate (ATP), and the degradation rate of organic compounds, referred to as volatile solids, increased with ATP concentration. The by-products generated from ZFWS comply with the national standard for organic fertilizer.
\end{abstract}

Keywords: Bio wood chips, Composting, Fermentation-extinction technique, Food waste, Sustainability

\section{Introduction}

Rapid urbanization and industrialization driven by intensive economic development has transformed the urban landscape of South Korea, with large-scale and high-density housing. A massive supply of apartments in the second half of the twentieth century has changed the profile of the national housing stock; the proportion of this type of housing has grown from $7.0 \%$ in 1960 to $59.0 \%$ in 2010 such that the proportion of total households residing in this housing jumped from $4.9 \%$ in 1960 to $47.1 \%$ in 2010 [1-3]. With the growing number of households (from 8 million in 1960 to 17.3 million in 2010) [2-3], modernized lifestyles have increased the generation of both household waste and food waste (Fig. 1). Thus, high-density living coupled with a wide array of daily activities has substantially contributed to global warming.

Climate change is one of the world's greatest issues, and the Paris Agreement, adopted in 2015, sought to mitigate global warming. Efforts to significantly reduce the emission of carbon

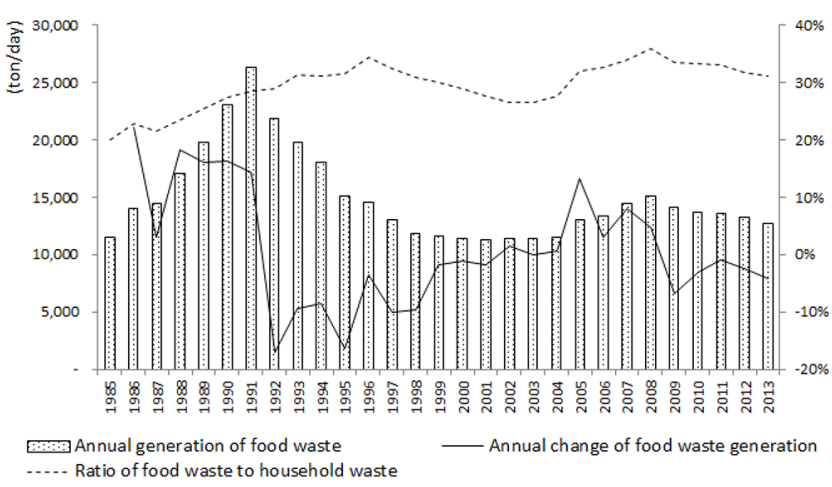

Fig. 1. Food waste generation in Korea.

Source: KME (1993 to 2014)

dioxide $\left(\mathrm{CO}_{2}\right)$ in high-density housing, where many people live and their daily activities occur, are important. $\mathrm{CO}_{2}$ is widely known as a major greenhouse gas in the building industry, and its reduction is imperative [4-6].
This is an Open Access article distributed under the terms of the Creative Commons Attribution Non-Commercial License (http://creativecommons.org/licenses/by-nc/3.0/) which permits unrestricted non-commercial use, distribution, and reproduction in any medium, provided the original work is properly cited.
Received January 22, 2017 Accepted July 30, 2017

${ }^{\dagger}$ Corresponding author

Email: ecohousing@khu.ac.kr

Tel: +82-2-961-9192 Fax: +82-2-961-9192 
As the pressure to provide low-impact housing increases, numerous technologies have been applied to drastically lower carbon emissions in apartment complexes, which in turn reduces greenhouse gases, prevents global warming and tackles climate change [7-8]. Food waste in apartment complexes is considered a primary factor in quality of living and has gained attention as an important pool of biomass that can reduce carbon emissions [9-14]. In fact, the main source of food waste generation in South Korea is the residential environment, and in 2010 , more than one-quarter of household waste $(28.8 \%)$ was food waste [15]. Given that local governments are responsible for managing food waste in their jurisdiction and a substantial portion of the budget is allocated to management costs, recycling food waste is important and becomes more important as the 1996 London Protocol affects the nation. In fact, the annual waste management cost of the nation continues to grow, and the proportion of the cost to the national expenditure was $1.4 \%$ in 2010 [12, 13, 16].

While much food waste has been recycled (Fig. 2), the recycling is largely limited to livestock feed and fertilizer. Innovative techniques for both food waste reduction and the recycling of food waste into useful resources have been discussed. When food waste can be disposed of with adequate bio-energy techniques in apartment complexes, a zero food waste system (ZFWS) becomes an ideal and practical solution [17-18]. In fact, food waste daily produced in each unit of Korean apartment complexes is usually brought to a designated food waste collection bin within the complex, and the collected food waste is transported to a range of waste treatment plants such as incineration, anaerobic-aerobic digestion, compost and recycling facilities. On the contrary to the current food waste management system, the ZFWS treats food waste by using eco-friendly technology, so-called a fermentation-extinction technique, which makes use of bio wood chips, and also by-products in the technological process can be recycled as composts or bio fuels.

The purpose of this study is to explore the ZFWS embedded in a fermentation-extinction technique using bio wood chips. The performance of the system will be investigated in an apartment complex.

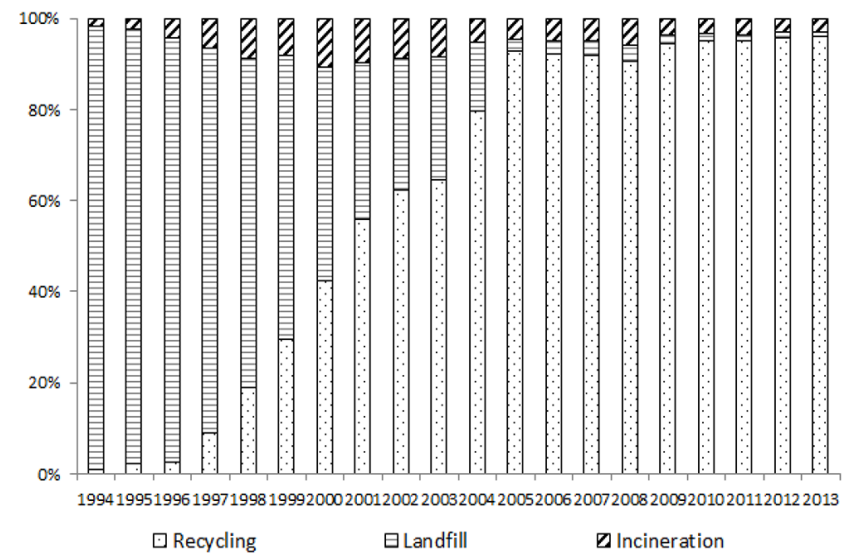

Fig. 2. Disposal of food waste in Korea.

Source: KME(1993 to 2014)

\section{The Concept of a Zero Food Waste System}

In South Korea, food waste produced in each unit of an apartment complex is brought to a designated waste collection bin in the complex. The collected food waste is transported by trucks to a range of waste treatment plants, such as incineration, anaerobic-aerobic digestion, composting and recycling facilities. The current handling is accompanied by an offensive odor and leachate, leading to complaints.

A ZFWS specifies that food waste is treated with environmental friendly technology by using a fermentation-extinction technique, which uses bio wood chips to improve porosity. In this system, food waste is immediately recycled into composts or biofuels. Thus, ZFWS not only reduces food waste but also recycles it into useful resources. Not only can the system create a living environment that virtually eliminates food waste but also organic fertilizer, the by-products of the ZFWS, can be used in gardens of apartment complexes. In fact, the innovative system can provide an opportunity to enable residents to grow fruits and vegetables in their community garden of an apartment complex, stimulating residents' participation in community activities leading to a sense of community.

Fig. 3 illustrates how a ZFWS works in an apartment complex. The diagram indicates that food waste generated at home is not stored, packed and collected for further treatment or management. The by-products from the ZFWS can be used as an organic fertilizer for gardening in apartment complexes, so this innovative system can stimulate an opportunity for building community by allow residents to get involved in a community garden and its activities.

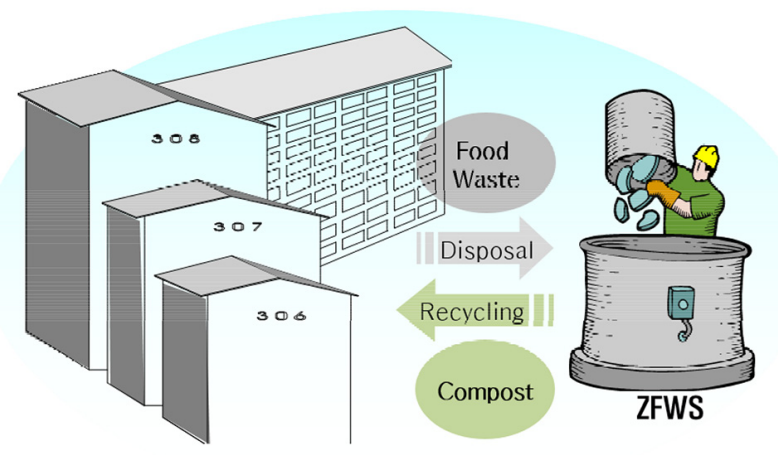

Fig. 3. Schematic diagram of zero food waste system (ZFWS). Source: Oh \& Lee (2013)

\section{Materials and Methods}

\subsection{Experimental Set-up of the ZFWS}

To test the performance of the ZFWS, a field experiment was conducted in a large-scale apartment complex in Seoul, Korea. The experimental ZFWS was designed to treat $50 \mathrm{~kg}$ of food waste per day and consisted of 3 technical parts (Fig. 4). The first constituent was a fermentation-extinction reactor, which mixes food waste with bio wood chips exclusively made up of complex en 

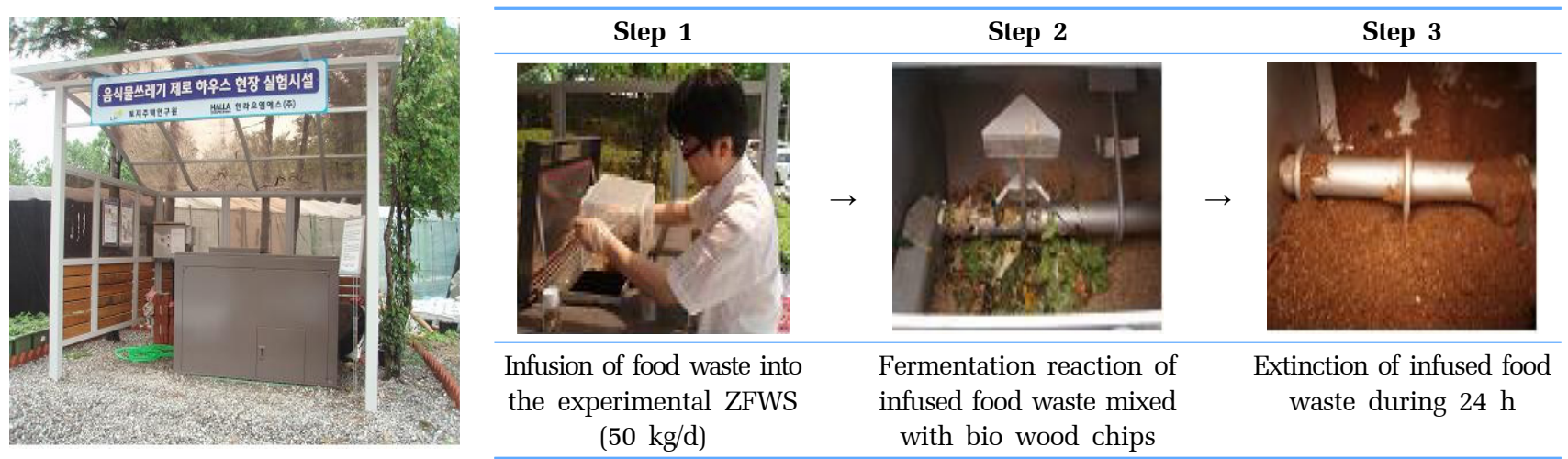

Fig. 4. In situ experimental setup of the ZFWS for the disposal of food waste in an apartment complex.

Source: LHI(2012)

Table 1. Details of ZFWS's Field Experimentation

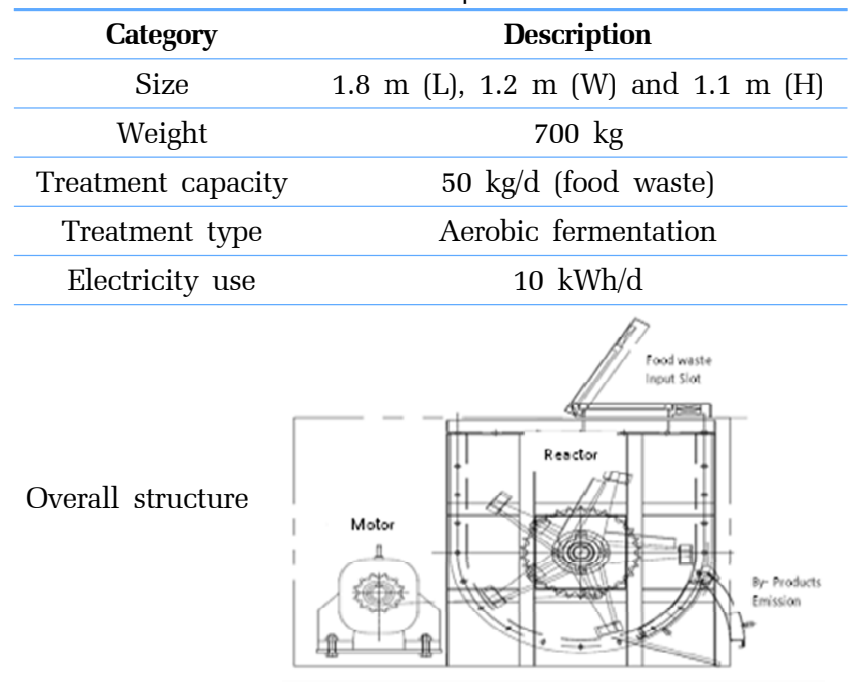
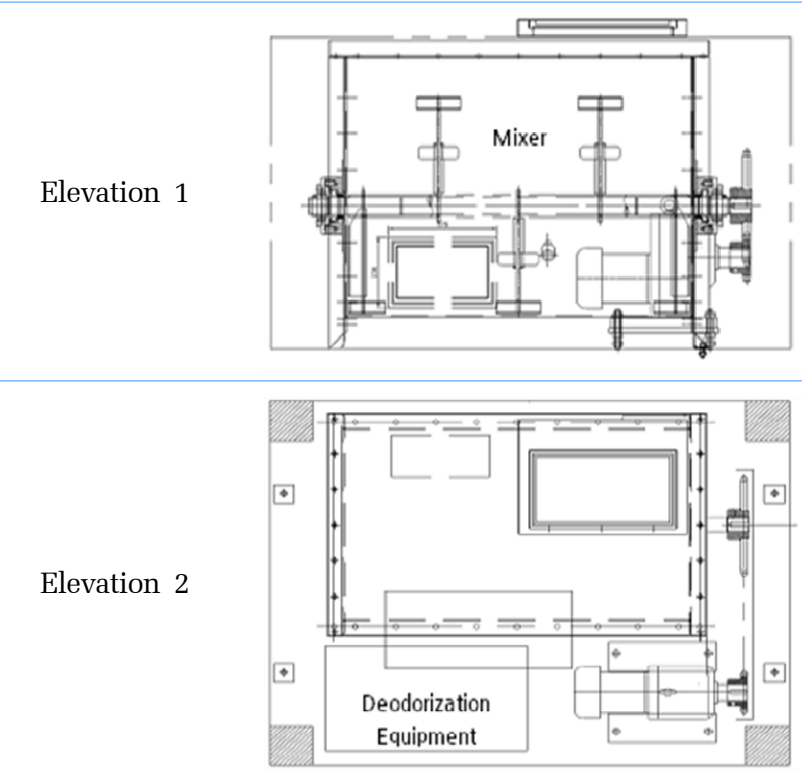

Source: LHI (2012) zymes and aseptic wood chips. These ingredients are supposed to ensure free air space to adequately supply oxygen, to minimize foul odor and to reduce volatile organic compound (VOC) emission. The second component was deodorizing equipment in which an ultraviolet (UV) light and ozone photolysis method was employed. The last element was a food waste slot into which food waste brought by residents was injected.

The established ZFWS was $1.8 \mathrm{~m}$ long, $1.2 \mathrm{~m}$ wide and 1.1 $\mathrm{m}$ tall, weighed $700 \mathrm{~kg}$, and consumed $10 \mathrm{~kW}$ per day of electricity in Table 1. Food waste was treated with an aerobic fermentation-extinction technique using bio wood chips which contain complex enzymes and aseptic wood chips [19-20].

\subsection{Operation and Monitoring of the ZFWS Field Experiments}

The on-site ZFWS was operated and controlled through constant conditions (Table 2). To adequately mix food waste with bio wood chips in the fermentation-extinction reactor, the temperature was maintained between $30^{\circ} \mathrm{C}$ and $40^{\circ} \mathrm{C}$. The air supply to the fermentation-extinction reactor was not measured.

In the beginning of the ZFWS field experiments, $50 \mathrm{~kg}$ of bio wood chips were placed in the fermentation-extinction reactor, and on average $11 \mathrm{~kg}$ of food waste per day were injected during the experimental period. While there was no additional placement of bio wood chips during the experiment, mixtures of food waste and bio wood chips in the fermentation-extinction reactor slowly removed its moisture during the operation, maintaining a moisture content (MC) of $30 \%$ to $50 \%$. The food waste was mixed at between 2 and $10 \mathrm{rpm}$ to maintain the proper ambient temperature and aerobic pores. It can be adjusted to vary operational conditions. When running the ZFWS, the daily electricity use was on average $6.2 \mathrm{kWh}$, and it cost approximately $485 \mathrm{KRW} / \mathrm{kWh}$ (3,007 KRW per day per household).

$\mathrm{pH}$ and salinity adjustments of the fermentation-extinction reactor were controlled to maintain the equal distribution of bio wood chips and food waste and the recirculation of fermented by-products, which are used to revitalize microbial activity. Adequate ventilation of the fermentation-extinction reactor was used to remove objectionable odors. The odor was sucked out through deodorizing equipment when the food waste slot of the ZFWS opens or closes, and UV and ozone photolysis reactions worked to remove the odors. 
Table 2. Description of ZFWS Field Experiments

\begin{tabular}{ll}
\hline \multicolumn{1}{c}{ Category } & \multicolumn{1}{c}{ Description } \\
\hline Temperature of the reaction & $30-40^{\circ} \mathrm{C}$ \\
Used bio wood chips & $50 \mathrm{~kg}$ \\
Maximum capacity of injected food waste & $50 \mathrm{~kg} / \mathrm{d}$ \\
Running period & $220 \mathrm{~d}$ \\
Mixing velocity & $2-10 \mathrm{rpm}$ (food waste \& bio wood chips) \\
Adjustments of pH and salinity & Distribution of bio wood chips, recirculation of by-products \\
Deodorization & Air ventilation of the reactor to deodorization the equipment \\
\hline
\end{tabular}

\subsection{Chemical Analysis of the ZFWS's Food Waste Inputs and Residues}

The ZFWS field experiment was conducted from July 8, 2011 to February 12, 2012. During the 220-day experiment, food waste was injected into the ZFWS on a daily basis, and the efficiency of the food waste treatment was assessed by comparing the total loading of food waste inputs to food waste mixtures with bio wood chips in the fermentation-extinction reactor.

Injected food waste and mixtures of food waste and bio wood chips in the fermentation-extinction reactor were analyzed for volatile solids (VS), pH, salinity, and adenosine tri-phosphate (ATP). ATP was a good indicator of microbial activity associated with the bio wood-chips in the fermentation-extinction reaction.

\section{Results}

\subsection{Weight Reduction of Food Waste}

The weight change between food waste inputs and food waste residues in the field experiment of the ZFWS was investigated. Amount of daily injected food waste ranged from $18.5 \mathrm{~kg}$ to 25 $\mathrm{kg}$ during the 220-day experiment. The weight variations during the experimental period are summarized in Table 3. The amount of injected food waste in the on-site ZFWS was $2,465 \mathrm{~kg}$ in total, but the food waste residues after the fermentation-extinction reaction weighed $145 \mathrm{~kg}$. Thus, the treatment efficiency of food waste for the ZFWS is $94 \%$. Food waste in the fermentation-extinction reaction might be removed within $24 \mathrm{~h}$, before the next injection of food waste into the ZFWS.

Table 3. Weight Change of Food Waste Inputs and Residues in the ZFWS

\begin{tabular}{ccc}
\hline Category & $\begin{array}{c}\text { Start date } \\
\text { (Jul. 8) }\end{array}$ & $\begin{array}{c}\text { End date } \\
\text { (Feb. 12) }\end{array}$ \\
\hline Accmulative input of food waste & - & $2,465 \mathrm{~kg}$ \\
Loading of bio wood chips & $50 \mathrm{~kg}$ & $50 \mathrm{~kg}$ \\
Food waste residues & - & $145 \mathrm{~kg}$ \\
Treatment efficiency & - & $94 \%$ \\
\hline
\end{tabular}

\subsection{Composition Analysis}

The composition analyses of the injected food waste and food waste residues were carried out. There are five indicators for the mixture of food waste and bio wood chips in the fermentation-extinction reactor - MC, VS, salinity, $\mathrm{pH}$, and ATP (Fig. 5).

Moisture Content (MC): The field experiment revealed clear differences in the MC of food waste inputs and food waste residues (Fig. 5(a)), which demonstrates the fluctuations in MC; the horizontal axis (x-axis) displays the experimental period of the ZFWS (220 d in total), and the vertical axis (y-axis) describes the changing $\mathrm{MC}$ of the injected food waste and the mixtures of food waste and bio wood chips in the fermentation-extinction reaction. The MC of injected food waste was an average of $74.2 \%$ (with a minimum of $34.7 \%$ and a maximum of $92.3 \%$ ), while the $\mathrm{MC}$ of the mixture in the reactor was an average of $39.0 \%$ (with a minimum of $27.0 \%$ and a maximum of $62.7 \%$ ). On average a $35.2 \%$ decrease in $\mathrm{MC}$ was recorded during the experimental process.

Volatile Solids (VS): The mean concentration of VS for the injected food waste was $90.9 \%$, ranging from $60.8 \%$ to $99.2 \%$ (Fig. 5(b)). The VS concentrations for the mixtures retrieved from the fermentation-extinction reactor $24 \mathrm{~h}$ later were between $64.4 \%$ and $91.0 \%$, with an average of $80.6 \%$.

The early stage of the experimental period was during early summer (from July to August of 2011), so the VS concentration of the mixtures remained between $70 \%$ and $80 \%$. In the middle of the experimental period, autumn (from September to November), the VS concentration varied between $80 \%$ and $90 \%$. As the experimental period approached its end, the organic VS stabilized at approximately 80\% during the winter (from December to February). Consequently, the ZFWS, through the fermentation-extinction reaction, resulted in an approximately $10 \%$ reduction in organic compounds. It was shown that the organic compounds of the by-products generated from the fermentation-extinction reaction stayed constant, although the weight change for the injected food waste was $94 \%$ in the system. In addition, the by-products of the fermentation-extinction reaction in the ZFWS satisfied the national standard for organic fertilizer in South Korea, which requires at least 70\% organic compounds. Even as the injected food waste in the ZFWS accumulated over time, the mixtures in the fermentation-extinction reaction maintained a steady level of VS without controlling the bio wood chips.

Salinity: The salinity of the injected food waste fell between $0.1 \%$ and $1.1 \%$, and the average value was $0.23 \%$ (Fig. 5(c)). 
(a)

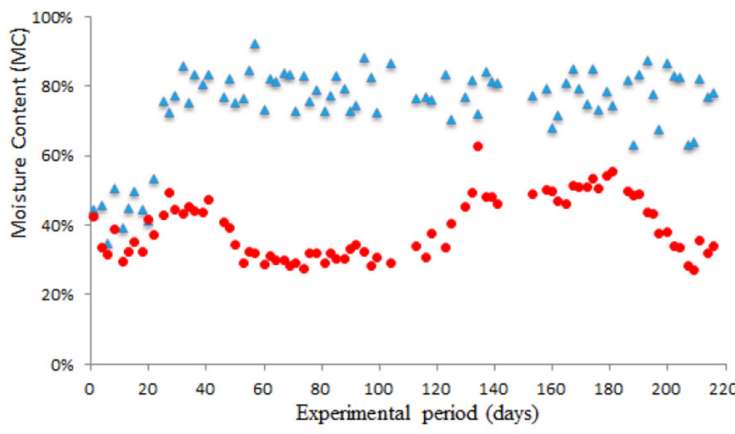

$\Delta$ Injected food waste (input)

- Mixture (throughput)

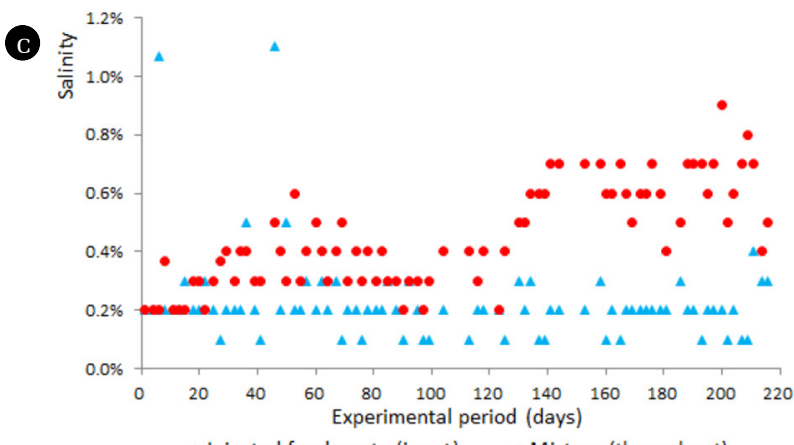

$\Delta$ Injected food waste (input) $\quad$ Mixture (throughput)

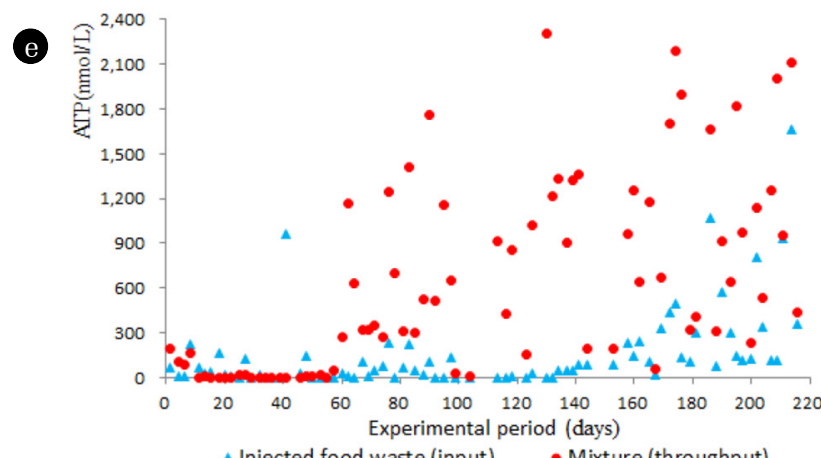

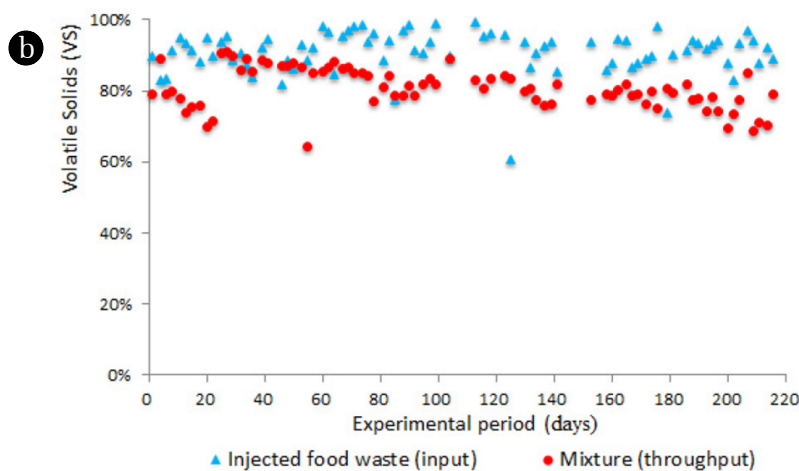

(a)

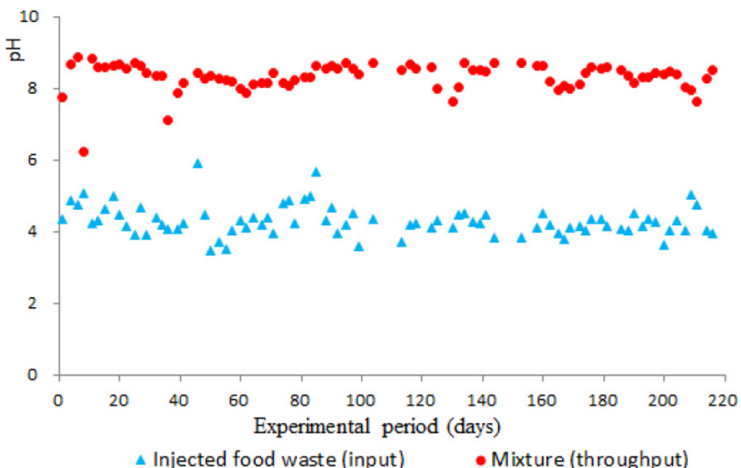

- Mixture (throughput)

Fig. 5. Changing moisture content (MC) (a), volatile solids (VS) (b), salinity (c), pH (d) and ATP (e) of the injected food waste and mixtures of food waste and bio wood chips in the ZFWS.

Mixtures of food waste and bio wood chips in the fermentation-extinction reaction were examined $24 \mathrm{~h}$ after injection, and the salinity changed from $0.2 \%$ to $0.9 \%$, and the mean value was $0.45 \%$. The salinity of mixture in the reactor was found to be approximately half that of the injected food waste. The decreasing values can be attributed to the moisture loss of the food waste in the process of the fermentation-extinction reaction.

The salinity in the reactor gradually accumulated and became slightly elevated over the experimental period. Since the field experiment started in early summer (from July to August of 2011), the salinity of the mixture was reduced to $0.4 \%$. In autumn (from September to November of 2011), the salinity dropped between
$0.3 \%$ and $0.6 \%$. In winter, when the experiment finished (December of 2011), the salinity of the mixture gradually rose and was maintained between $0.5 \%$ and $0.9 \%$.

pH: An acidic $\mathrm{pH}$ contained in the injected food waste ranged from 3.5 to 5.9, and the mean value was 4.3 (Fig. 5(d)). Within $24 \mathrm{~h}$ of the initial injection, mixtures in the fermentation-extinction reaction were collected and examined. The $\mathrm{pH}$ scale varied from 6.2 to 8.9 , and the average value was 8.3 , indicating a low alkaline $\mathrm{pH}$. The results delineate that an adequate ratio of injected food waste to bio wood chips was reducing acidity and moving toward alkalinity as the fermentation-extinction reaction progressed to an alkaline $\mathrm{pH}$ level. It was also noted that by-products of the fermentation-extinction reaction re- 
mained at a constant alkaline $\mathrm{pH}$ even though food waste was continuously added to the ZFWS during the experimental period. More importantly, the $\mathrm{pH}$ level of the mixture in the fermentation-extinction reaction was continuously stable without controlling bio wood chips despite food waste being gradually injected on a regular basis.

Adenosine tri-phosphate (ATP): The ATP concentration of the injected food waste was on average $157 \mathrm{nmol} / \mathrm{L}$ (with a minimum of $4.1 \times 10^{-4} \mathrm{nmol} / \mathrm{L}$ and a maximum of $1,660 \mathrm{nmol} / \mathrm{L}$ ) (Fig. 5(e)). From mixtures in the reactor retrieved $24 \mathrm{~h}$ later, the ATP concentration was on average $631.2 \mathrm{nmol} / \mathrm{L}$ (with a minimum of 5.8 $\times 10^{-2} \mathrm{nmol} / \mathrm{L}$ and a maximum of $2,310 \mathrm{nmol} / \mathrm{L}$ ).

Because it widely known that ATP is an important catalytic component of microbial metabolism, the results imply that biological activities of microorganisms increased with ATP hydrolysis. By extension, the ATP concentration of the mixtures in the fermentation-extinction reaction of the ZFWS escalated as the experiment steadily progressed. In other words, the ratio of injected food waste to bio wood chips was adequate. While the amount of injected food waste in the ZFWS was mounting over time, the mixtures in the reactor remained at a constant level of ATP without controlling the bio wood chips, which implies that microbial activities in the fermentation-extinction reactor of the ZFWS became stable. ATP is regarded as a good indicator in assessing organic degradation, so the compound is useful to detect the effects of the bio wood chips in the fermentation-extinction reaction.

\subsection{Comparison of the ZFWS's Composition}

Moisture Content (MC) and Volatile Solids (VS): Two sets of composition analyses were conducted on both the injected food waste and the mixtures of food waste and bio wood chips in the fermentation-extinction reaction of the ZFWS. As presented in Fig. 6, the first pair is the association of MC with VS, and as injections of food waste escalated, the fermentation-extinction reactor of the ZFWS lowered the MC and maintained the concentrations of VS at a stable level. In other words, the by-products of the mixture ensure a high quality of compost which conforms to the national standard for an organic fertilizer.

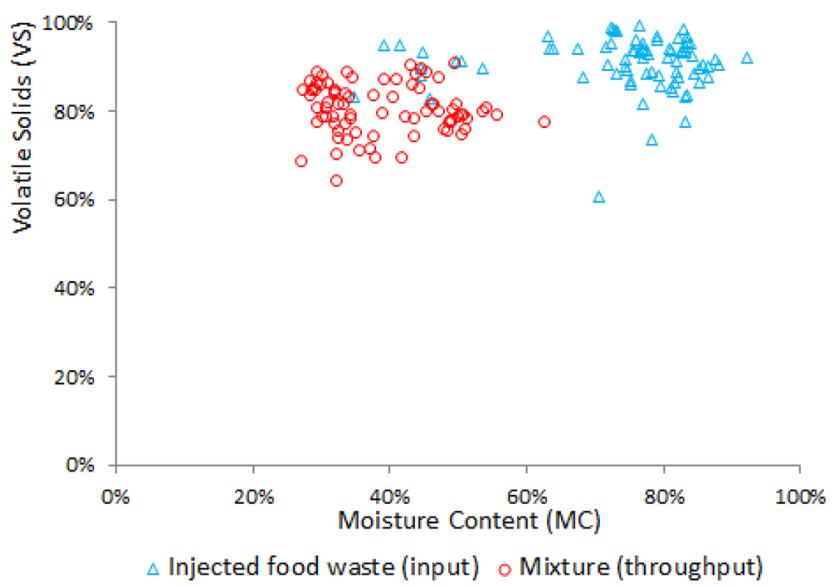

Fig. 6. Distribution of the MC and the VS of injected food waste and mixtures of food waste and bio wood chips in the ZFWS.
Salinity and pH: Fig. 7 describes the relationship between the salinity and $\mathrm{pH}$ of injected food waste and mixtures of food waste and bio wood chips in the ZFWS. This second pair shows that both salinity and $\mathrm{pH}$ substantially decreased throughout the fermentation-extinction reaction of the ZFWS. While the ZFWS constantly received food waste during the experimental period, the reactor lowered these two components, and the mixtures stayed at a constant level of alkaline $\mathrm{pH}$ and a lower level of salinity, producing by-products that can used as an organic fertilizer.

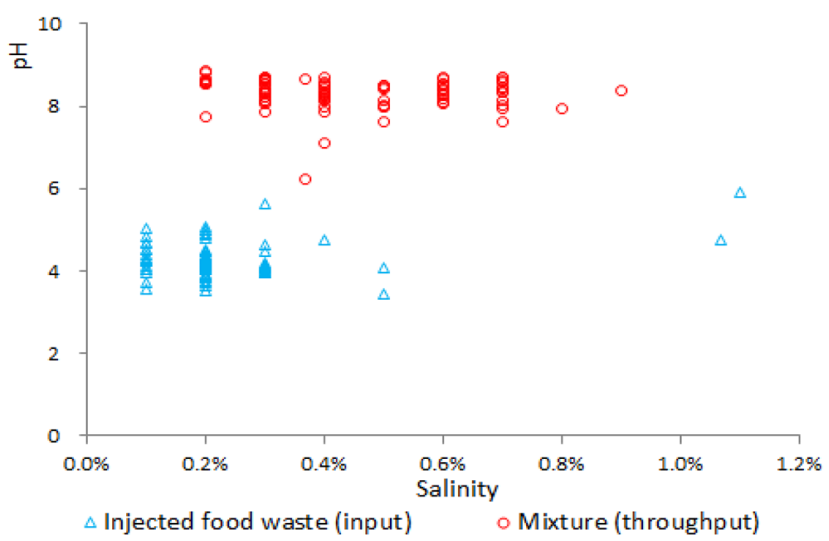

Fig. 7. Distribution of salinity and $\mathrm{pH}$ of injected food waste and mixtures of food waste and bio wood chips in the ZFWS.

\subsection{Microbial Activities in the ZFWS}

To assess the performance of the fermentation- extinction reaction and to elaborate on the ZFWS model, the microbial activity of the mixtures of food waste and bio wood chips was analyzed during the experimental period. ATP was examined in association with 4 components - MC, VS, salinity and $\mathrm{pH}$ (Figs. 8-11, respectively). The findings revealed that the ZFWS stabilizes the MC between $30 \%$ and $50 \%$, maintains VS between $70 \%$ and $90 \%$, lowers the salinity below $0.8 \%$, and maintains a $\mathrm{pH}$ value of approximately 8. All the indicators show that microbial activities occur in a stable and consistent way, supporting that the ZFWS produces a high quality of organic fertilizer by fully using the food waste.

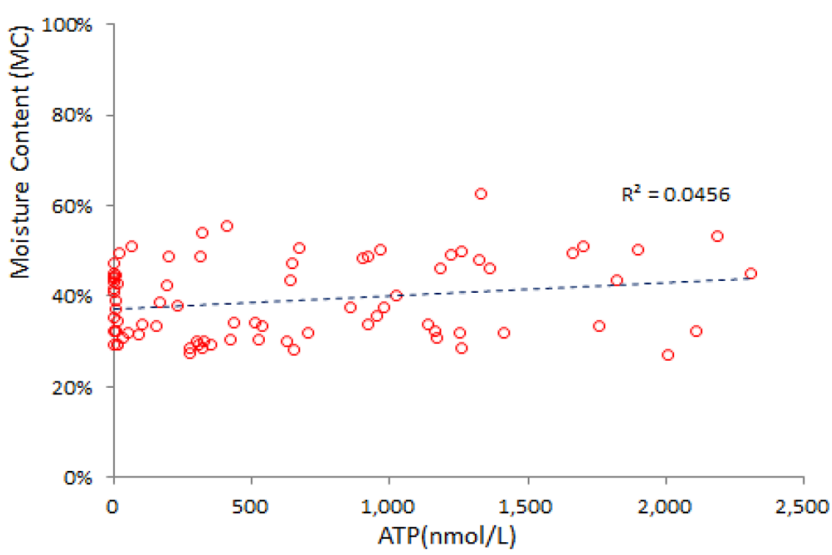

Fig. 8. Distribution of ATP and MC in mixtures of food waste and bio wood chips. 


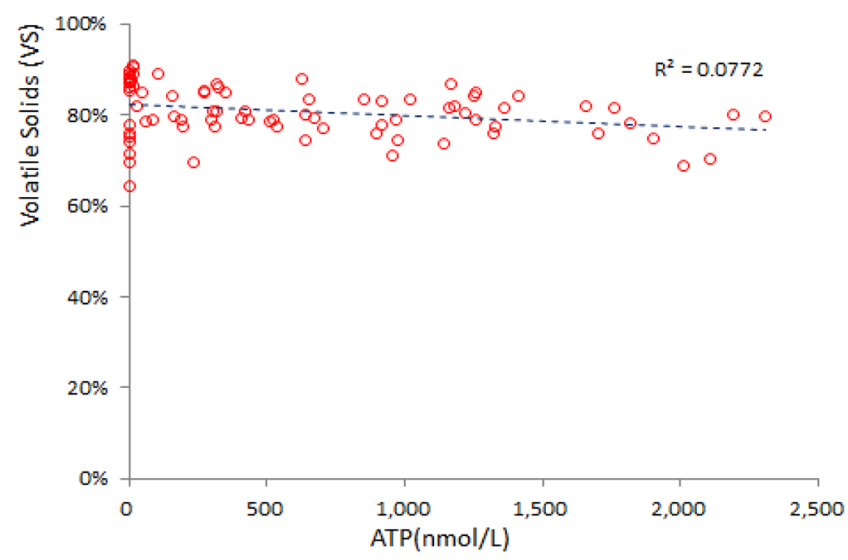

Fig. 9. Distribution of ATP and VS in mixtures of food waste and bio wood chips.

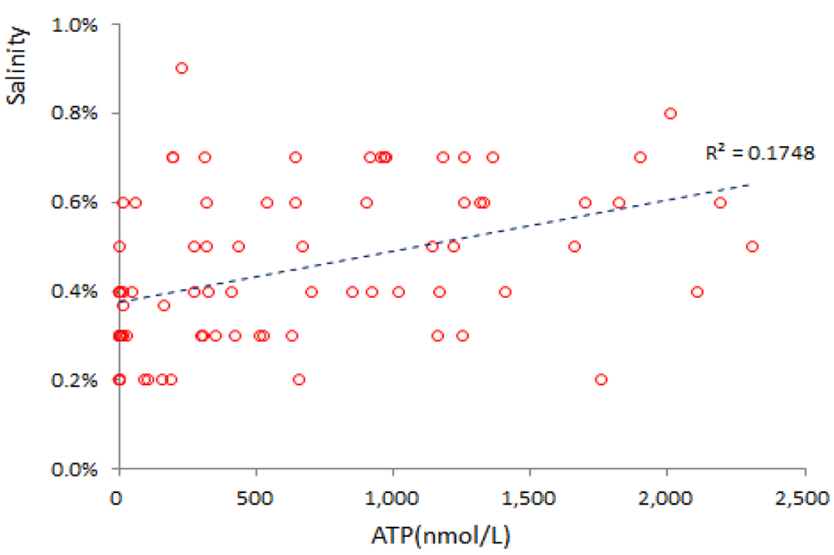

Fig. 10. Distribution of ATP and salinity in mixtures of food waste and bio wood chips.

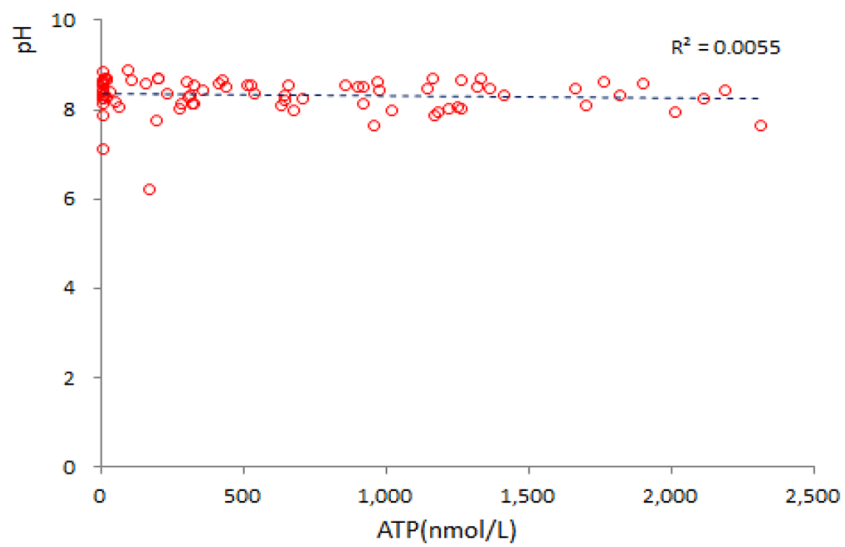

Fig. 11. Distribution of ATP and $\mathrm{pH}$ in mixtures of food waste and bio wood chips.

\section{Conclusions}

This research proposed the ZFWS with fermentation-extinction technology using bio wood chips as a new approach to reduce carbon dioxide emissions, divert climate change and make the residential environment more sustainable. To evaluate the performance of the ZFWS, a field experiment was conducted on a large-scale apartment complex. The on-site ZFWS treated up to $50 \mathrm{~kg}$ of food waste per day for $220 \mathrm{~d}$, and the treatment efficiency of the food waste was assessed by comparing the weights of both food waste inputs and food waste residues mixed in the fermentation-extinction reactor.

The field experiments found that the food waste residues in the ZFWS weighed $145 \mathrm{~kg}$, while a total amount of food waste injected into the ZFWS during the experimental period was 2,465 $\mathrm{kg}$. Consequently, the treatment efficiency of the food waste was $94 \%$. A composition analysis was made within $24 \mathrm{~h}$ of food waste injections into the ZFWS. The moisture content was on average $35.2 \%$ and decreased between food waste inputs and food waste residues. The mixtures in the reactor of the ZFWS maintained a constant level of VS, pH, salinity, and ATP without controlling the bio wood chips during the experimental period. It was found that quality of the by-products generated from the fermentation-extinction reaction in the ZFWS fulfilled the national standards for organic fertilizer, which demand at least $70 \%$ organic compounds. Therefore, the research implies that the ZFWS is not just an alternative solution to ensuring the quality of the residential environment in a sustainable way but also a stepping stone for mitigating the global environmental crisis.

\section{Acknowledgments}

This research was supported by a grant (17AUDP-B083704-04) from the Architecture \& Urban Development Research Program funded by the Korea Ministry of Land, Infrastructure and Transport.

\section{References}

1. KMOLIT. Korea Ministry of Land, Infrastructure and Transport statistics system [Internet]. c2016 [cited 10 Nomvember 2016]. Available from: http://stat.molit.go.kr/portal/main/portalMain.do.

2. Statistics Korea. e-National indicators [Internet]. c2016a [cited 17 Nomvember 2016]. Available from: http://www.index.go. $\mathrm{kr} /$ potal/main/EachPage.do?mmenu $=2 \& \mathrm{smenu}=12$.

3. Statistics Korea. Statistical information [Internet]. c2016b [cited 17 Nomvember 2016]. Available from: http://kosis.kr/statisticsList/statisticsList_01List.jsp?vwcd=MT_ZTITLE\&parentId=A.

4. Kharseh M, Altorkmany L. How global warming and building envelope will change buildings energy use in central Europe. Appl. Energ. 2012;97:999-1004.

5. Lau LC, Lee KT, Mohamed AR. Global warming mitigation and renewable energy policy development from the Kyoto Protocol to the Copenhagen Accord: A comment. Renew. Sust. Energ. Rev. 2012;16:5280-5284.

6. Kaku K. Global warming and climate change of Asian countries including Japanese domestic greenhouse gas (GHG) reduction in the field of poultry and swine industries. Procedia Eng. 2011;8:511-514.

7. Choi IY, Cho SH, Kim JT. Energy consumption characteristics 
of high-rise apartment buildings according to building shape and mixed-use development. Energ. Buildings 2012;16:123-131.

8. Jeong YS, Lee SE, Huh JH. Estimation of $\mathrm{CO}_{2}$ emission of apartment buildings due to major construction materials in the Republic of Korea. Energ. Buildings 2012;49:437-442.

9. Habib K, Schmidt JH, Christensen P. A historical perspective of global warming potential from municipal solid waste management. Waste Manage. 2013;33:1926-1933.

10. Kim MH, Song YE, Song HB, Kim JW, Hwang SJ. Evaluation of food waste disposal options by LCC analysis from the perspective of global warming: Jungnang case. Waste Manage. 2011;31:2112-2120.

11. Lebersorger S, Schneider F. Discussion on the methodology for determining food waste in household waste composition studies. Waste Manage. 2011;31:1924-1933.

12. Oh J, Lee H. Exploring residents' attitudes in multi-family housing toward food waste zero-emission system with fermentation and extinction technology. J. Korean Soc. Environ. Eng. 2013;35:321-333.

13. Oh J, Lee H. Experimental evaluation and resident's assessment of zero food waste system in multi-family housing estates. J. Korean Soc. Environ. Eng. 2015;37:674-681.
14. Oh J, Lee H, Seok H. An analysis of food waste generation of residents and food waste resources in multifamily housing. J. Korean Soc. Environ. Eng. 2010;32:905-915.

15. KME. Annual statistics of waste production and management. Seoul: Korea Ministry of Environment; 1993 to 2014.

16. KMSF. 2012 National balance report. Gwacheon, South Korea. Korea Ministry of Strategy \& Finance; 2012.

17. LHI. A study on on-site practicalization of food waste zero house system by using fermentation extinction technology. Daejeon, South Korea. Korea Land and Housing Institute of the Korea Land and Housing Corporation; 2012.

18. LHI. A study on the analysis of operational status for automatic municipal waste collection facilities in the development district. Daejeon, South Korea. Korea Land and Housing Institute; 2015.

19. LHI. Application of food waste-zero emission system to apartment complexes. Daejeon, South Korea. Korea Land and Housing Research Institute; 2010.

20. Oh JI. Variation of adenosine tri-phosphate (ATP) in fermentation-extinction of food wastes with wood bio-chip. J. Korean Soc. Environ. Eng. 2010;32:363-368. 